OBSERVATIONS

\title{
Adulteration of food: what it doesn't say on the tin
}

The horse meat scandal is just the latest sign that we need a concerted effort to change our collective food culture

\author{
Gabriel Scally director, WHO Collaborating Centre for Healthy Urban Environments, University of \\ the West of England
}

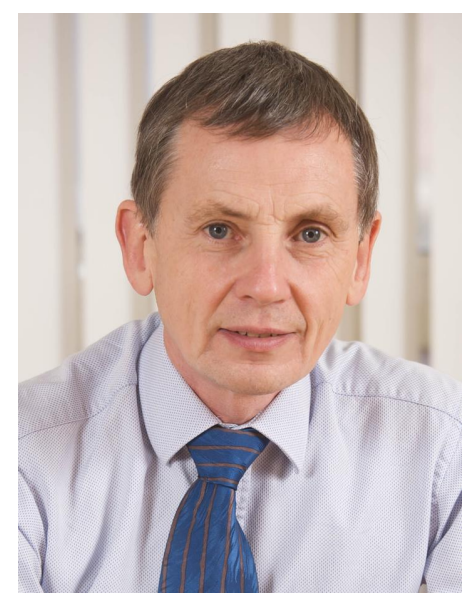

There's nothing new about the adulteration of food. The opportunity to increase profit by surreptitiously substituting inferior ingredients has tempted unscrupulous conmen and women down the centuries. Indeed, what is held to be the very first piece of public health legislation passed by the Westminster parliament was the 1757 "Act for the due making of Bread; and to regulate the Price and Assize thereof; and to punish Persons who shall adulterate Meal, Flour, or Bread." The current horse meat scandal, which was first exposed in Ireland and has now reached across Europe, shows only that modern food processing has created the opportunity to practise fraud on consumers on a truly massive and international scale. It remains to be seen whether any wrongdoers are punished.

But this isn't the first major crisis in the United Kingdom's food system. In recent decades there has been the bovine spongiform encephalopathy problem, which resulted in deaths from variant Creutzfeldt-Jakob disease, and the 2001 foot and mouth outbreak, which devastated farming communities and has been strongly associated with subsequent serious mental health problems. Both of these damaging transmissible disease problems exposed the enormity of the changes that have taken place in our food system.
The lengthening of supply chains, including the movement of animals and animal produce across borders and sometimes continents, accompanied by the increased industrialisation of the food business, has had a profound effect on the food culture of developed countries. The UK, in particular, has seen its food retail sector becoming increasingly dominated by a small number of very large supermarket chains and very substantial growth in the market for highly processed food. This domination by what we can justifiably term the "food-industrial complex" has created a system that is profoundly unsustainable. The huge volume of wasted food and unnecessary packaging; the destruction of fish stocks; the substantial proportion of the UK's greenhouse gas emissions associated with the food chain; the continuing rise in levels of childhood obesity-all testify to a degraded food culture that is, in itself, a major threat to the health and wellbeing of the population.

At one stage the government's response to this degraded food culture did look promising. The 2002 report on the foot and mouth outbreak wanted to see "a farming and food sector that is profitable and sustainable, that can and does compete internationally, that is a good steward of the environment and provides healthy food to people in England and around the world."1 The Labour government's official position was eventually formulated, and the Cabinet Office's 2008 report advocated the creation of "a future of food that is far more sustainable-economically, environmentally and socially. It is a future where consumers are able to access healthy, low-impact food that fits their lifestyles and time pressures."2

Ever since the coalition government came to power in 2010 any slight momentum towards change established in the previous decade has dissipated. The abandonment of work on the Healthier Food Mark that was to be applied to all public catering; the abolition of the Healthy Schools programme; the exemption of academies and free schools from school nutrition standards; the creation by the Department of Health of the much derided "responsibility deal," where the nine-strong steering group on food has six members from the food-industrial complex; the short lived Cabinet Sub-committee on Public 
Health. All this points to the adoption of laissez faire as the standard operating procedure for population health in England. The response from the health department to these profound changes in food culture has been remarkably muted. Despite obesity becoming a major driver of non-communicable disease, attention has often been concentrated on the nutritional content of the food available rather than on the steady degradation of the whole relation between people and the food they eat. Nor has the medical profession quite realised the seriousness and reach of the food problem. The recent response from the UK's Academy of Medical Royal Colleges to the obesity epidemic, though promising a campaign on some far sighted recommendations, shied away from tackling the underlying malaise. ${ }^{3}$

The only appropriate response to this crisis is a concerted effort to change our collective food culture. It should start with the reintroduction of protection of prime agricultural land from building developments; include support for sustainable agriculture that produces food for our tables that is local, traceable, and nutritious; free school meals for all children in state schools; robust curbs on the promotion of foods high in fat, sugar, and salt; and a rebalancing of food retailing towards covered markets and small and medium sized local shops on our high streets. Or will we sit back and wait for the next crisis?

Competing interests: GS is a trustee of the Soil Association.

Provenance and peer review: Not commissioned; not externally peer reviewed.

Policy Commission on the Future of Farming and Food. Farming and food: a sustainable future. Jan 2002. http://webarchive.nationalarchives.gov.uk/20100807034701/http:/archive. cabinetoffice.gov.uk/farming/pdf/PC\%20Report2.pdf.

2 Cabinet Office Strategy Unit. Food matters: towards a strategy for the 21st century. Jul 2008. http://webarchive.nationalarchives.gov.uk/+/http:/www.cabinetoffice.gov.uk/media/ cabinetoffice/strategy/assets/food/food matters1.pdf.

3 Academy of Medical Royal Colleges. Measuring up: the medical profession's prescription for the nation's obesity crisis. 2013 www.aomrc.org.uk/publications/statements/cat_view. html.

Cite this as: BMJ 2013;346:f1463

@ BMJ Publishing Group Ltd 2013 